\title{
El Magistrado Constitucional
}

OtTo MARRoquín GUERRA

Magistrado Vocal III

Cámara de Amparos y Antejuicio de la Corte Suprema de Justicia de Guatemala

\section{Los tribunales constitucionales en Iberoamérica}

e entiende por Tribunales Constitucionales, a los altos órganos judiciales o
jurisdiccionales situados dentro o fuera del poder judicial, independientemente de su denominación, cuya función material esencialmente consiste en la resolución de los litigios o conflictos derivados de la interpretación o aplicación directa de la normativa constitucional.

Esa tendencia cobra relevancia en el ámbito iberoamericano, especialmente a partir de la segunda mitad del siglo xx, al surgir o consolidarse órganos de esta naturaleza con distintos matices y modalidades:

a) Sean como tribunales o cortes constitucionales autónomos ubicados fuera del aparato jurisdiccional ordinario (Chile, Ecuador, España, Guatemala, Perú y Portugal);

b) Como tribunales o cortes autónomos dentro de la propia estructura del poder judicial (Bolivia y Colombia);

c) En calidad de salas especializadas en materia constitucional pertenecientes a las propias cortes o tribunales supremos (El Salvador, Costa Rica, Nicaragua, Paraguay y Venezuela),

d) $\mathrm{O}$ bien como cortes o tribunales supremos ordinarios realizando funciones de tribunal constitucional, aunque no de manera exclusiva (Argentina, Brasil, Honduras, México, Panamá y Uruguay).

Este devenir hacia una magistratura constitucional especializada también encuentra eco en ciertos tribunales transnacionales, al realizar una función semejante a la de los tribunales constitucionales en el ámbito interno, mediante una labor interpretativa de los tratados y convenios internacionales. Actualmente, esta función la emprende la Corte Interamericana de Derechos Humanos con sede en la ciudad de San José, Costa Rica, cuya competencia contenciosa ha sido reconocida por Guatemala y Nicaragua. 


\section{Antecedentes históricos}

En la Edad Media aparece en el Reino de Aragón una figura encargada de velar por el cumplimiento exacto de los diversos fueros, conocido como el Justicia Mayor. Este alto funcionario actuaba como un verdadero "juez constitucional" al amparar a los solicitantes sobre sus bienes, derechos y persona, al hacer respetar un alto ordenamiento como lo fue el "privilegio general", en el cual se establecieron ciertos derechos fundamentales.

El justicia mayor actuaba en los procesos aragoneses de aprehensión, de inventario, de firma de derecho y de manifestación de personas.

Destaca el último de estos procesos, en el que se facultaba a la justicia o a sus lugartenientes, miembros de su corte o tribunal, a emitir una orden mandando a cualquier juez u otra persona que tuviera ante sí a un preso, pendiente o no de causa, para que se lo entregasen, a fin de que no se hiciese violencia alguna contra él antes de que se dictase sentencia.

Después de lo cual, si la sentencia no estaba viciada, el justicia ordenaba la entrega del preso a la autoridad que sobre él había sentenciado, para que dicha sentencia se cumpliese del modo ordinario.

También en Inglaterra surgió en el siglo XVII un instrumento de índole procesal para proteger el derecho de libertad. El Habeas Corpus se reguló de una manera detallada en la Habeas Corpus Amendment Act de 26 de mayo de 1679, por lo que se ha considerado a este ordenamiento el primero en reglamentar meticulosamente un proceso constitucional.

Al fundarse las colonias inglesas en Estados Unidos de América se transplantó el "common law" y con éste la institución del habeas corpus. Actualmente en aquel país se conoce como un writ (junto con otros como el "writ of certiorari", writ of quo warranto, writ of injuction), constituyendo esencialmente un mandato $\mathrm{u}$ orden tendente a la defensa de la libertad del individuo contra actos ilegales de la autoridad o de particulares.

Mientras que en la Nueva España (México) paulatinamente se fue estructurando un sistema de legalidad, en Estados Unidos de América se consolidó un sistema de control constitucional, a partir del famoso caso "Marbury vs. Madison", fallado por la Corte Suprema el 24 de febrero de 1803, mediante resolución del juez presidente JOHN MARSHAL, en la que se sostuvo que la Constitución es una ley y como tal, puede ser el fundamento de un reclamo en un juicio ordinario. Sin embargo, tuvo que pasar más de un siglo, para que en 1958 la propia Corte Suprema en el caso "Cooper vs Aaron" sostuviera por vez primera que dicho 
alto tribunal se constituía como el intérprete final y supremo de la Constitución criterio que se consolidó fundamentalmente a finales del siglo XIX.

\section{Sistema de control difuso}

De esta forma nace el sistema de control constitucional conocido como "americano" o "difuso", llamado así debido a que cualquier juez ordinario puede decidir sobre la conformidad de la ley aplicable al caso concreto con la Constitución, sea de oficio o a petición de parte (vía incidental). La resolución que en estos casos se dicte consiste en desaplicar la ley contraria a la Constitución en el caso particular.

Este sistema americano de revisión judicial de la constitucionalidad de las leyes influyó en gran parte de los ordenamientos latinoamericanos, especialmente debido a la difusión que tuvo la conocida obra de ALEXIS DE TOCQUEVILLE: La Democracia en América, traducida al español en 1837 por SÁNCHEZ DE BUSTAMANTE.

En contrapartida al sistema americano de control constitucional, después de la primera guerra mundial surge en Europa otro sistema que, en teoría resulta diametralmente opuesto. Como veremos más adelante, este sistema "europeo" tiene como característica fundamental la existencia de un tribunal o corte constitucional ad hoc que se encargaba de resolver los conflictos o cuestiones de inconstitucionalidad de las disposiciones legislativas impugnadas, teniendo sus resoluciones efectos generales para el futuro.

\section{Nacimiento de los Tribunales Constitucionales y su expansión en Europa África y Asia.}

La Constitución de Checoslovaquia de 29 de febrero de 1920 representa el primer ordenamiento en prever formalmente un tribunal constitucional. Sin embargo, es la alta corte constitucional austríaca, -introducida unos meses después en la Constitución del 1 de octubre del mismo año- la que ha servido de modelo al denominado sistema "europeo" o "austríaco" de control constitucional, adoptado progresivamente y con matices propios por numerosos ordenamientos constitucionales de Europa, África, Asia y América Latina.

\section{Evolución de tribunales constitucionales}

En la evolución de los tribunales constitucionales se pueden distinguir con claridad tres etapas:

a) La primera, que constituye el nacimiento de los tribunales constitucionales durante los primeros años posteriores a la primera guerra mundial. En este 
primer periodo se crea el Tribunal Constitucional de Checoslovaquia y la Alta Corte constitucional de Austria (1920); esta última, por inspiración del aquel entonces profesor de derecho público y de filosofía del derecho en la Universidad de Viena, Hans Kelsen, siendo el primer ponente permanente de dicha Corte desde su incorporación en 1921 hasta la reforma de dicho órgano en 1929. En esta etapa también aparece en España el Tribunal de Garantías Constitucionales previsto en la Constitución Republicana de 1931, entre cuyas facultades principales correspondía conocer el recurso de amparo de garantías individuales.

b) La segunda, constituye la legitimación y expansión de los tribunales constitucionales, fundamentalmente en Europa Occidental a partir de la culminación de la segunda guerra mundial. Este periodo se inicia con la reinstalación de la Corte constitucional austríaca en 1945 (que había sido desplazada por un Tribunal Federal en la Constitución de 1934, tras el golpe de estado en 1933). En los años siguientes se dio la expansión en Europa Occidental al crearse los tribunales constitucionales italianos (1948), constitucional federal alemán (1949), también el Consejo constitucional francés (1959), tribunal constitucional turco $(1961,1982)$ y tribunal constitucional yugoslavo $(1963,1974)$.

c) La tercera, surge a partir de la década del setenta, con la expansión de dichos tribunales. Así se crean los tribunales constitucionales portugués $(1976,1982)$, griego (1975, Tribunal Especial Superior), español (1978), y belga (1980, denominado Tribunal de Arbitraje). Posteriormente estos órganos especializados en materia constitucional se expandieron en Europa del Este y en la ex Unión Soviética, Polonia (1982, 1986, 1997), Hungría (1989), Croacia (1990), Checoslovaquia, Rumania, Bulgaria y Eslovenia (1991), Albania, Eslovaquia, Estonia, Lituania, Macedonia, República Checa y lo que resta de Yugoslaviafederación de Servia y Montenegro (1992), República Federal Rusa, actualmente unida con Bielorrusia (1993), Moldavia (1994), Bosnia-Herzegovina (1995), Letonia (1996) y la República de Ucrania, integrante de la Comunidad de Estados Independientes (1996) y Guatemala (1985).

En esta tercera etapa deben incluirse también la Corte Constitucional de Sudáfrica (1994, 1997), los altos tribunales constitucionales en Madagascar (1975) y en Egipto (1979), así como el Tribunal Constitucional surcoreano (1987), entre otros.

\section{Los tribunales, cortes y salas constitucionales en Iberoamérica}

En la actualidad a nivel iberoamericano existen: a) cortes o tribunales constitucionales que se encuentran fuera del poder judicial (Chile, Ecuador, España, 
Guatemala, Perú y Portugal), b) tribunales constitucionales situados dentro del poder judicial (Bolivia y Colombia); c) salas constitucionales autónomas que forman parte de las cortes supremas (El Salvador, Costa Rica, Paraguay, Nicaragua y Venezuela); d) además de las cortes o supremos tribunales ordinarios que realizan funciones de tribunales constitucional, aunque no de manera exclusiva (Argentina, Brasil, Honduras, México, Panamá y Uruguay).

\section{Tribunales y Cortes Constitucionales fuera del poder judicial}

GUATEMALA. Al margen de los antecedentes de Cuba y de Ecuador, el primer tribunal constitucional autónomo en América Latina -desde su perspectiva formal y material- fue la "Corte de Constitucionalidad de Guatemala, prevista por los artículos 262 a 265 de la Constitución de 15 de septiembre de 1965. Esta Corte no tenía el carácter de permanente, integrándose cada vez que se intentaba una acción constitucional, por lo que en la práctica conoció de pocos asuntos. Se formaba por 12 miembros: cuatro designados por la Corte Suprema de Justicia (el presidente de la misma también fungía como presidente de la Corte Constitucional) y los restantes por sorteo que realizaba la propia Corte Suprema entre magistrados de la Corte de Apelaciones y del Tribunal de la Contencioso Administrativo.

La nueva Constitución de 31 de mayo de 1985, que entró en vigor el 14 de enero de 1986, dedica el capítulo VI a las "Garantías constitucionales y defensa del orden constitucional". De manera específica en su artículo 268 introduce una Corte de Constitucionalidad establecida como "un tribunal permanente de jurisdicción privativa, cuya función esencial es la defensa del orden constitucional; actúa como tribunal colegiado con independencia de los demás organismos del Estado y ejerce funciones especificas que le asigna la constitución y la ley de la materia". Conoce fundamentalmente de tres procesos constitucionales: la exhibición personal (babeas corpus), el amparo y la declaratoria de inconstitucionalidad de las leyes. Estos procesos constitucionales se regulan por la Ley de Amparo, Exhibición Personal y de Constitucionalidad de 1986.

Se compone de cinco magistrados titulares y sus respectivos suplentes. Son designados para cinco años, teniendo cada uno de ellos extracción distinta al ser designados por el pleno de la Corte Suprema de Justicia, el pleno del Congreso de la República, el presidente de la república en Consejo de ministros; el Consejo Superior Universitario de la Universidad de San Carlos de Guatemala, y la Asamblea del Colegio de Abogados.

CHILE. El artículo 81 de la Constitución vigente, aumenta a siete los magistrados integrantes del Tribunal: tres magistrados de la Corte Suprema elegidos por 
dicha Corte en votación secreta, y cuatro abogados de reconocido prestigio (dos nombrados por el Consejo de Seguridad Nacional, uno por el presidente de la república y uno por el Senado). Entre las facultades del Tribunal Constitucional se encuentran el control preventivo de constitucionalidad de los preceptos legales y el conocimiento de las instituciones del amparo (recurso de protección) y del habeas corpus.

ECUADOR. Inicialmente se integraba por once miembros, reduciéndose a nueve a partir de las reformas constitucionales de 1996, nombrados por el Congreso Nacional de entre las sendas ternas propuestas por el presidente de la república; Corte Suprema de Justicia; Congreso Nacional; alcaldes municipales y perfectos provinciales; centrales de trabajadores y organizaciones indígenas y campesinos de carácter nacional legalmente reconocidos; y por las Cámaras de Producción también legalmente reconocidas.

ESPAÑA. La actual Constitución democrática de diciembre de 1978, crea un Tribunal Constitucional compuesto por doce magistrados nombrados formalmente por el rey, aunque elegidos por los tres poderes clásicos del estado: ocho designados por las Cortes generales (cuatro por el Congreso de los Diputados y cuatro por el Senado); dos por el Consejo General del Poder Judicial; y los otros dos por el gobierno. Su encargo dura un periodo de nueve años y se renuevan por terceras partes cada tres, no pudiendo ser reelegidos inmediatamente.

PORTUGAL. La Constitución de la República Portuguesa, de 1976, define al Tribunal Constitucional como el tribunal competente para la administración de la justicia en materias de naturaleza jurídico - constitucionales y se instituye como uno de los poderes del estado. Se integra por trece miembros nombrados por un periodo de nueve años, sin que puedan ser reelectos, siendo diez elegidos por la Asamblea de la República y los tres restantes por los propios miembros electos. De los trece integrantes, por lo menos seis de ellos tienen que ser escogidos entre los jueces de los otros tribunales (Supremo Tribunal de Justicia o tribunales judiciales de primera y segunda instancia; Supremo Tribunal Administrativo o de los demás tribunales administrativos y fiscales; o del tribunal de Cuentas), y los restantes entre los ciudadanos que tengan el grado académico en derecho (licenciatura, maestría o doctorado).

\section{Tribunales constitucionales dentro del poder judicial}

Colombia. Los artículos 239 a 245 de la nueva Constitución colombiana de 7 de julio de 1991 introduce la Corte Constitucional, compuesta por nueve magistrados designados por el Senado de la república de entre las ternas que formulan el 
presidente de la república, la Corte Suprema de Justicia y el Consejo de Estado. Los magistrados son nombrados por un periodo de ocho años sin poder ser reelectos. La Corte Constitucional colombiana que se ha caracterizado por su rica e importante jurisprudencia, conoce de la acción de tutela jurídica (amparo), acción de habeas corpus acciones populares y acciones de clase, relacionadas con la defensa de ciertos derechos constitucionales.

\section{Salas constitucionales pertenecientes a las cortes supremas}

El Salvador. La Constitución de 15 de diciembre de 1983 crea la Sala de lo Constitucional de la Corte Suprema de Justicia (art.174). Si bien esta sala, compuesta por magistrados para un periodo de nueve años, forma parte de la propia Corte Suprema, materialmente se puede considerar como un tribunal constitucional actuando en forma autónoma, teniendo como competencia la resolución de los procesos constitucionales de habear corpus, amparo e inconstitucionalidad de leyes.

\section{Salas constitucionales pertenecientes a cortes supremas}

Nicaragua. Conforme a la actual Constitución de Nicaragua de noviembre de 1986 (reformada en 1995), la Corte Suprema de Justicia se integra por dieciséis magistrados electos por la Asamblea Nacional para un periodo de cinco años, y se integra por varias salas, entre las que destaca la Sala de lo Constitucional. En general, la Corte Suprema conoce del recurso por inconstitucionalidad de leyes, decretos o reglamentos, del recurso de amparo, y del recurso de exhibición personal (babeas corpus), previstos en el Titulo X, Capitulo II, denominado "Control Constitucional" (arts. 187 a 190). La ley de Amparo de noviembre de 1988 reglamenta estos tres recursos.

\section{Salas constitucionales pertenecientes a cortes supremas}

Costa Rica con interesantes antecedentes, la reforma constitucional de 18 de agosto de 1989 a la Constitución de 1949, incorpora una Sala de Constitucionalidad de la Corte Suprema de Justicia (conocida como la Sala Cuarta). El artículo 10 constitucional establece la facultad de la sala especializada para declarar, por mayoría absoluta de sus miembros, la inconstitucionalidad de las normas de cualquier naturaleza y de los actos sujetos al derecho público, especificando que no serán impugnables en esa vía los actos jurisdiccionales del poder judicial, la declaratoria de elección que haga el Tribunal Supremo de Elecciones y los demás que determine la ley. 
La sala se integra por siete miembros y por los suplentes que la ley determine y serán elegidos por la Asamblea Legislativa. Se incluyen además, Paraguay y Venezuela.

\section{La Corte Interamericana como Intérprete Constitucional}

La tutela de los derechos humanos se realiza fundamentalmente en el ámbito interno de los Estados -dimensión que CAPELLETTI califica como la "jurisdicción constitucional de las libertades"-, especialmente a partir de la segunda posguerra, habiéndose creado sistemas para la protección de los derechos humanos en el ámbito regional e internacional, con un carácter subsidiario y complementario a los establecidos en los ordenamientos internos, lo que ha producido la "internacionalización de los derechos humanos" y, con ellos, la creación de organismos jurisdiccionales supranacionales especializados en la materia, lo que dio origen a la distensión que el propio CAPELLETTI bautizó como "la jurisdicción internacional de las libertades".

Siguiendo el modelo europeo, paulatinamente se configuró el Sistema Internacional de Derechos Humanos, cuya culminación puede decirse representa la Corte Interamericana de Derechos Humanos, con sede en San José, costa Rica, establecida como consecuencia de la entrada en vigor de la Convención Americana sobre Derechos Humanos o "Pacto de San José” (18 de julio de 1978), comenzando sus funciones en junio de 1979.

La Corte se constituye como un órgano judicial autónomo del sistema interamericano aunque con nexos con la Comisión Interamericana, compuesta por siete jueces, cuyo objetivo esencial representa la interpretación y aplicación de la Convención Americana referida y de sus dos protocolos adicionales: a) en Materia de Derechos Económicos, Sociales y culturales o "Protocolo de San Salvador" (Primer Protocolo), y b) Relativo a la Abolición de la Pena de Muerte (Segundo Protocolo). Este marco de aplicabilidad debe completarse además con la convención Americana para Prevenir y Sancionar la Tortura (1987) la Convención Interamericana para Prevenir, Sancionar y Erradicar la Violencia contra la Mujer (1995) Convención Americana sobre Desaparición Forzada de Personas (1996), y recientemente la Convención Interamericana para la eliminación de todas las formas de discriminación contra las personas con discapacidad (2001).

El Estatuto de la Corte le otorga esencialmente dos funciones: a) una consultiva, que consiste en la emisión de opiniones que le soliciten los Estados miembros u órganos de la Organización de los Estados Americanos respecto a la interpretación de la Convención o de otros tratados en lo relativo a la protección de los derechos humanos en los Estados americanos 
En cuanto a su composición orgánica, en ambos casos se integran por jueces independientes, cuyos miembros no son numerosos, nombrados por un periodo más o menos largo (teniendo en cuenta que si bien en el caso de la corte es de seis años, pueden ser reelegidos por un nuevo periodo), y en cuanto a sus funciones, sobre todo la contenciosa, el objetivo esencial consiste en la interpretación y aplicación de la Convención Americana como una especie de lex superior conteniendo un bill of rights trasnacional, teniendo sus resoluciones efectos vinculantes con los Estados que reconozcan su jurisdicción siendo inapelables.

Esto ha provocado que en la actualidad se encuentre en crisis el principio de supremacía constitucional y del concepto tradicional de soberanía (no sin cierta polémica entre internacionalistas y constitucionalistas), como se evidencia en el reciente caso La Ultima Tentación de Cristo (caso Olmedo Bustos y otros) resuelto el 5 de febrero de 2001, en el cual se condena al Estado chileno a que modifique su ordenamiento jurídico interno (incluida su Constitución) con el fin de suprimir la censura previa para permitir la exhibición de dicha película, al estimar que se violó el derecho a la libertad de pensamiento y de expresión, así como la libertad de conciencia y de religión, consagrados en los artículos 12 y 13 de la Convención Americana.

Así, la Corte Interamericana se establece como auténtico guardián e intérprete final de la Convención, al estimar que "en los casos en los que una disposición constitucional resulta incompatible con la Convención, el Estado parte está obligado, de conformidad con el artículo $2^{\circ}$, a adoptar las medidas legislativas (constitucionales y ordinarias) necesarias para hacer efectivos los derechos y libertades garantizados por la Convención".

Incluso en sus facultades consultivas se aproxima al control previo de constitucionalidad que realizan algunos tribunales, cortes y salas constitucionales. También existe similitud con las medidas provisionales que dicta la Corte en casos de extrema gravedad y urgencia, cuando haga necesario evitar daños irreparables a las personas, como sucede con la "suspensión del acto reclamado" en el recurso de amparo guatemalteco, en la medida en que se otorgue legitimación activa a los individuos para acceder directamente ante la corte Interamericana -que constituye una reforma previsible-, como acontece en Europa.

Existe un avance considerable en el nuevo Reglamento de la Corte Interamericana, aprobado el 24 de noviembre de 2000, que entró en vigor el 1 de junio del 2001, al otorgar participación directamente (locus standi in judicio) a las presuntas víctimas, sus familiares o sus representantes debidamente acreditados en todas las etapas del proceso, una vez iniciado éste mediante la presentación de la demanda ante el tribunal. 


\section{Requisitos propuestos por el Presidente del Tribunal Constitucional de Ecuador}

ECUADOR: Consideramos necesario referir el caso de Ecuador por que expresa uno de los mejores esfuerzos por lograr una mejor integración de la Corte de Constitucionalidad.

Así observamos que, para ser vocal magistrado del Tribunal Constitucional se deben reunir los mismos requisitos que para magistrado de la Corte Suprema de Justicia, esto es, además de los comunes como la nacionalidad de origen y el goce de derechos políticos, se exigen tres de capacidad e idoneidad personal: cuarenta y cinco años de edad, el grado académico de doctor en jurisprudencia, derecho o ciencias jurídicas y el ejercicio, con probidad notoria, de la cátedra en ciencias jurídicas, la profesión de abogado o la judicatura durante quince años.

Los requisitos señalados son de una alta exigencia en relación a los sistemas comparados en que se demanda una edad menor o un inferior tiempo de ejercicio profesional previo.

A pesar de lo señalado, no se ha tomado en cuenta que uno de los fundamentos para que el control de constitucionalidad se concentre en una magistratura especializada, propia del sistema kelseniano, a diferencia del sistema difuso, implantado en los Estados Unidos con el famoso y ya reseñado caso Marbury versus Madison resuelto por el Juez Marshall en 1803, es que el control de constitucionalidad sea ejercido con los patrones propios del Derecho Constitucional y sus principios, mas no con criterios civilistas, penalistas u otro que le son ajenos, además de que quienes lo resuelven deben ser especialistas en la materia.

Con ello, y por añadidura, a través del sistema de control concentrado se obtiene que los órganos creados para resolver temas no propiamente constitucionales, se puedan dedicar con mayor atención a resolver dichos asuntos.

\section{Propuesta del presidente constitucional de Ecuador}

\subsection{Requisitos}

Por lo expuesto, se infiere que para ser magistrado del Tribunal Constitucional debe acreditarse que el ejercicio profesional o la docencia se haya efectuado en materia constitucional, que se posean títulos de postgrado en el área del Derecho Público y Constitucional, o bien que la judicatura se haya practicado dentro de la Corte Suprema de Justicia, ora dentro de la jurisdicción constitucional, en especial si se crean, como se ha planteado en el proyecto de Ley Orgánica del Tribu- 
nal Constitucional, los jueces constitucionales, lo que favorece la especialización y tiende a asegurar la profesionalidad y experiencia del magistrado.

En todo caso, se plantea que en los sistemas constitucionales comparados que han seguido el modelo de control concentrado se limitan a exigir para los magistrados de las cortes o tribunales constitucionales los mismos requisitos que para magistrados de la Corte Suprema de Justicia, o sus similares, y se han integrado por jueces de distintas especializaciones jurídicas.

Por su parte Alemania establece que los magistrados que integran el Tribunal Constitucional Federal con el carácter de vitalicios debieron ser magistrados de las Cortes Supremas Federales, por que la magistratura constitucional representa el último gran escalón de la jerarquía jurisdiccional, a la que llegan con una amplia experiencia y conocimientos.

Con los datos anteriores consideramos que se puntualizan mejor los requisitos para optar al cargo de magistrado constitucional a fin de que se garantice mas el buen desempeño de tan importante cargo en la consolidación de la democracia en América Latina. 
